\title{
User Acceptance Enablers in Individual Decision Making About Technology: Toward an Integrated Model
}

\author{
Viswanath Venkatesh \\ University of Maryland, The Robert H. Smith School of Business, College Park, MD 20742, \\ e-mail:vvenkate@rhsmith.umd.edu \\ Cheri Speier \\ Michigan State University, Eli Broad College of Business, N215 North Business Complex, \\ East Lansing, MI 48823, e-mail: cspeier@msu.edu \\ Michael G. Morris \\ University of Virginia, McIntire School of Commerce, Monroe Hall, Charlottesville, VA 22904, \\ email: mmorris@virginia.edu
}

\begin{abstract}
Building on recent unique, yet potentially complementary, approaches to understanding the formation of user perceptions about technology (Venkatesh, 1999; Venkatesh \& Speier, 1999), the present work reanalyzes the data from both studies to develop an integrated model of technology acceptance. The integrated model specifically examines the influence of pre-training and training environment interventions (termed user acceptance enablers) to understand how user perceptions are formed prior to system implementation. The model is then further extended and tested using longitudinal data in a field setting. The results indicate that the integrated model emerged as a better predictor of user behavior when compared to the existing models.
\end{abstract}

\section{Subject Areas: Technology Acceptance and Training.}

\section{INTRODUCTION}

It is widely accepted that user training can have an important influence on technology acceptance and use (e.g., Davis, Bagozzi, \& Warshaw, 1989; Tannenbaum, 1990). It is therefore not surprising that organizations are expected to spend over $\$ 41$ billion on computer-related training by 2005 (IDC, 2001). Recently, two studies have looked at the issue of technology training, albeit through slightly different lenses. First, using the widely used technology acceptance model (TAM), Venkatesh (1999) manipulated the training environment to create a favorable short-term impact on user acceptance. Second, Venkatesh and Speier (1999) used the motivational model to focus on a pre-training intervention (specifically, mood) and demonstrated an immediate and ongoing impact on user acceptance. In the current work, we 
re-examine findings across these pre-training and training environment manipulations and theoretical perspectives to help develop a unified model that provides an integrated view of technology usage that is applicable across implementation contexts through a mechanism that we term "user acceptance enablers" (UAEs).

In addition to integrating the existing models, this research further extends our existing understanding of technology use by examining the degree to which the model predicts continued use of the technology. Research on technology acceptance often lacks a longitudinal dimension despite calls in the literature for such work (e.g., Adams, Nelson, \& Todd, 1992). Specific to this research, Venkatesh (1999) did not report any extended technology usage effects, while Venkatesh and Speier (1999) presented only a cross-sectional analysis of effects over time. In the current work, a formal longitudinal examination of a more robust theoretical model is given, providing a dynamic view of user acceptance.

In sum, the current work attempts to accomplish the following three objectives:

1. Extend our understanding of technology acceptance by integrating core concepts from the technology acceptance and motivational models and examining them longitudinally.

2. Understand the role of user acceptance enablers in the context of the integrated model.

3. Empirically test the models in a longitudinal setting to assess the explanatory power of the integrated model as compared to the existing models.

\section{THEORY DEVELOPMENT}

Venkatesh (1999) and Venkatesh and Speier (1999) presented crucial first steps to studying training-related interventions on user acceptance of technologies in realworld contexts (e.g., working professionals adopting technology in organizations). These studies used different theoretical frames and training interventions, and presented only limited insight into longitudinal technology usage effects. We extend that previous work by reviewing the two theoretical models and integrating these perspectives into a more comprehensive model of user acceptance of technologies in order to develop a richer understanding of technology acceptance and use over time.

\section{The Technology Acceptance Model and Training Environment Effects (Venkatesh, 1999)}

The technology acceptance model (TAM) (Adams et al., 1992; Davis et al., 1989; Mathieson, 1991) proposes two key determinants of intentions to use technologyperceived usefulness and perceived ease of use (Davis et al., 1989). Venkatesh (1999) applied TAM combined with a training manipulation to study user acceptance of a new technology, and the original model is shown in Figure 1. Results from this study demonstrated the short-term influence of an enjoyable (e.g., gamebased) training environment on intention to use a technology, where intention was mediated by perceived usefulness and ease of use. Usage behavior was not presented, and while intrinsic motivation (from the motivational model, discussed below) was measured, it was not linked theoretically or empirically to intention, perceived usefulness, or perceived ease of use. 
Figure 1: Venkatesh (1999) training environment model.

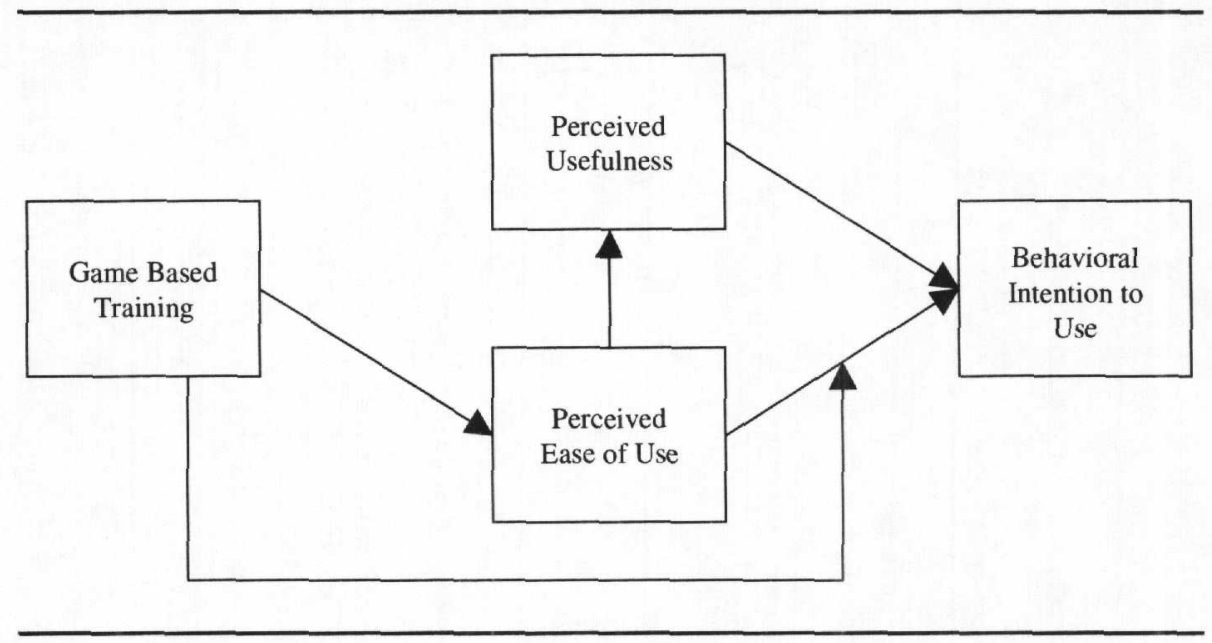

\section{Motivational Model and Pre-training Effects (Venkatesh \& Speier, 1999)}

The motivational model (MM) was adapted to user acceptance by Davis, Bagozzi, and Warshaw (1992). The model employs two key constructs: extrinsic motivation and intrinsic motivation. Venkatesh and Speier (1999) employed the motivational model to study the influence of pre-training mood (i.e., how one feels at a particular point in time, e.g., positive or negative) on user acceptance of technology over time, and the original model is presented in Figure 2. Although longitudinal usage was measured, the data were only analyzed cross-sectionally, potentially limiting our understanding of the underlying mechanisms influencing continued and extended technology use.

\section{Model Integration}

In order to integrate the two models of user acceptance, it is important to recognize some of the key similarities and distinctions between the motivational model (Davis et al., 1992) and TAM (Davis, 1989; Davis et al., 1989) at both a conceptual and operational level. Both the motivational model and TAM include a construct emphasizing an individual's personal gain associated with using a technology, termed extrinsic motivation and perceived usefulness, respectively. In fact, these two constructs were measured using the same items in the initial test of the two models (Davis et al., 1989, 1992), driving the integration of these two constructs into a single theoretical construct in the proposed model. For conceptual clarity, we have retained the "perceived usefulness" label from TAM, given its prevalence in the contemporary literature in this domain.

The motivational model also includes intrinsic motivation as a predictor or intention to use a technology, emphasizing the importance of having an enjoyable technology experience (Davis et al., 1992). In fact, research incorporating the intrinsic motivation construct has often operationalized it using items that tap "enjoyment" (e.g., Davis et al., 1992; Venkatesh \& Speier, 1999). TAM has no provision for intrinsic motivation or any related constructs (Davis et al., 1989). While 


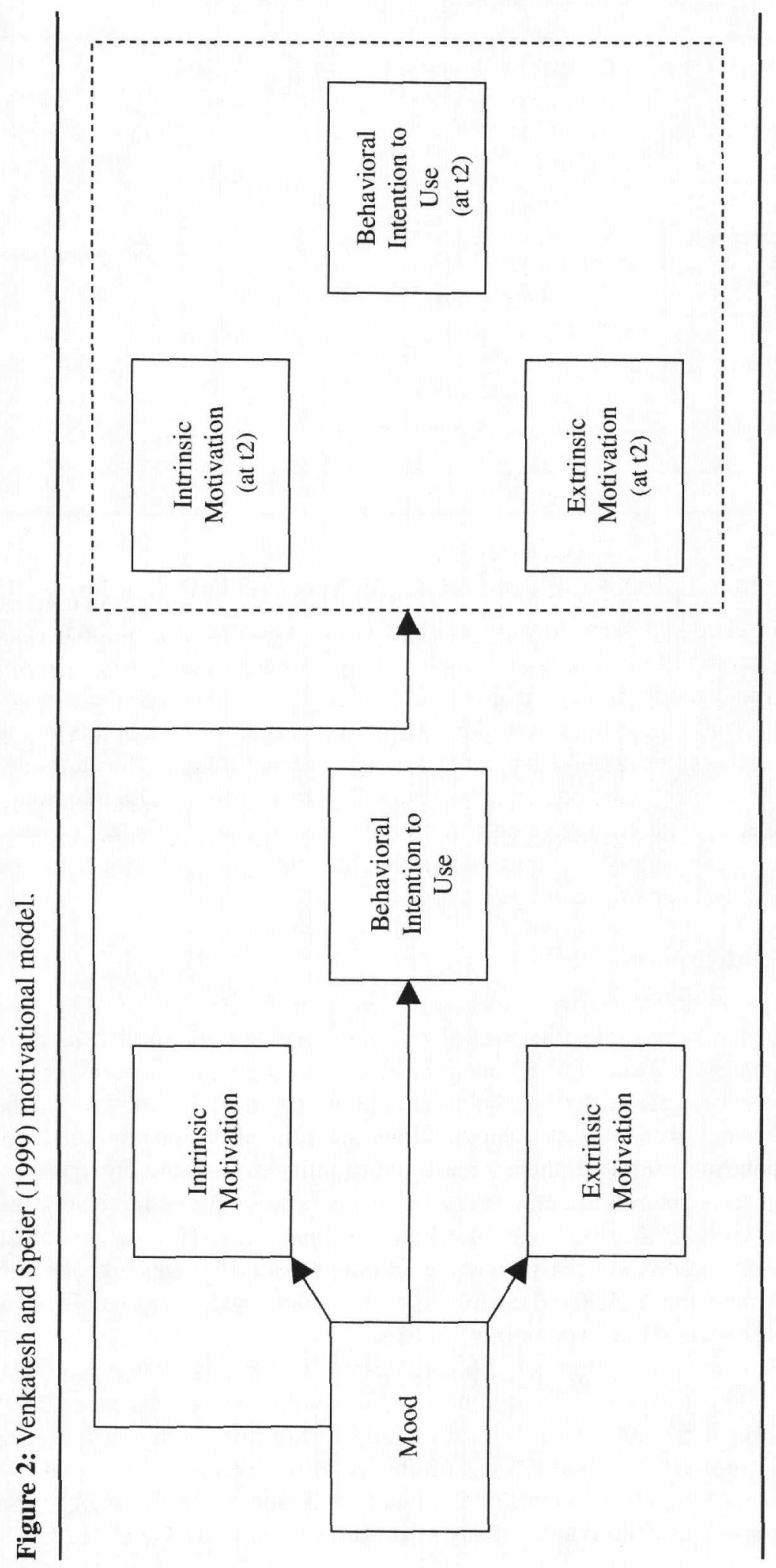

Reproduced with permission of the copyright owner. Further reproduction prohibited without permission. 
not including intrinsic motivation, TAM emphasizes perceived ease of use (e.g., the perception of effort associated with the use of a technology; Davis et al., 1989). Despite its widespread use within the user acceptance literature, perceived ease of use has not been incorporated into the motivational model (Venkatesh \& Speier, 1999). Therefore, in an effort to synthesize and extend the existing work, both intrinsic motivation (from MM) and perceived ease of use (from TAM) are featured in the proposed model (see Figure 3), along with perceived usefulness, which is common to both.

In building an integrated model of continued technology usage, we first present a baseline model of technology acceptance that integrates both TAM and motivational perspectives $(\mathrm{H} 1$ through $\mathrm{H} 6)$. We then examine the role of pre-training and training interventions (labeling these interventions as the more generalized construct "user acceptance enablers") to understand the formation of initial user perceptions that can be manipulated proactively $(\mathrm{H} 7)$. The overall fit of this model is then tested and compared to the existing models to determine which model provides the best understanding of the phenomenon (H8).

\section{Interrelationships Among Key Constructs and Intention}

The current research proposes a causal link from intrinsic motivation to perceived ease of use. Those who are more intrinsically motivated to use computer technologies are expected to indulge in using a new technology just for the sake of using it, in addition to using it for specific positive outcomes associated with use. Such individuals may tend to "underestimate" the difficulty associated with using a new technology because they enjoy the process and do not perceive it as being effortful compared to those who have less intrinsic motivation. More specifically, from a theoretical standpoint, research in psychology suggests that higher levels of intrinsic motivation typically lead to willingness to spend more time on the task (e.g., Deci, 1975), facilitating perceptions of ease of use.

$\mathrm{Hl}$ : Intrinsic motivation will have a significant positive influence on perceived ease of use.

The current research also proposes a causal path from intrinsic motivation to perceived usefulness. As alluded to earlier, research has shown that intrinsic motivation can have many beneficial effects on user behavior. For example, Starbuck and Webster (1991) demonstrated that intrinsic motivation can result in increased time spent on tasks and, therefore, higher quality output and more productive work-a concept tied to perceived usefulness. Intrinsic motivation increases the deliberation and thoroughness of cognitive processing (Bagozzi, Gopinath, \& Nyer, 1999; Mano, 1992) and leads to enhanced perceptions of extrinsic motivation (Batra \& Ray, 1986). Given this conceptual linkage between intrinsic perceived usefulness, we hypothesize:

H2: Intrinsic motivation will have a significant positive effect on perceived usefulness.

Research has also shown that perceived ease of use is a determinant of perceived usefulness (e.g., Davis et al., 1989; Taylor \& Todd, 1995; Venkatesh \& Morris, 2000). Thus, systems perceived as easier to use will facilitate system use 


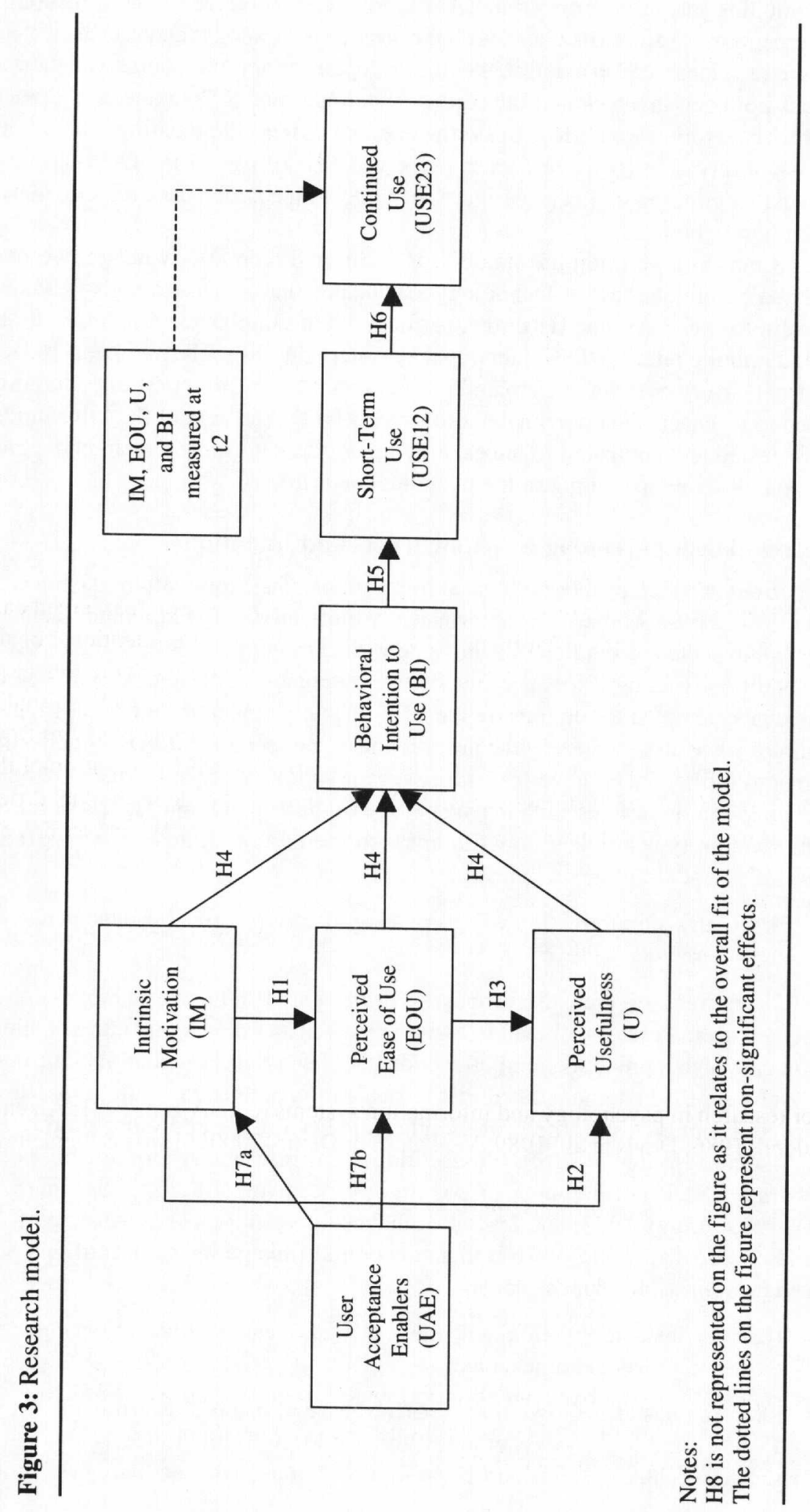


and task accomplishment more so than systems with lower ease of use. For example, personal computer users generally consider graphical user interfaces to be more useful when compared to older text-based interfaces because they are perceived to be easier to use-although objectively, they may not be more "useful" than the older style interface. Thus:

H3: Perceived ease of use will have a significant positive effect on perceived usefulness.

There is strong empirical evidence supporting the relationship between intrinsic motivation and extrinsic motivation/perceived usefulness influencing intention to perform an activity such as technology use (Davis et al., 1992; Vallerand, Fortier, \& Guay, 1997). Research suggests that for behaviors that are not purely intrinsic in the first place-for example, workplace technology usage behavior-extrinsic and intrinsic motivations play an additive role in explaining intentions and behavior (e.g., Calder \& Staw, 1975; Deci, 1975). Thus, in the context of this study, it is expected that both perceived usefulness (as an extrinsic motivator) and intrinsic motivation will influence intention to use a technology in an additive manner, consistent with prior empirical findings (Davis et al., 1992; Venkatesh \& Speier, 1999).

In addition to perceived usefulness and intrinsic motivation, perceived ease of use should also act as a significant determinant of behavioral intention, consistent with findings across varied organizational contexts and technologies (e.g., Davis et al., 1989; Morris \& Dillon, 1997; Venkatesh \& Davis, 1996). Finally, prior psychological research on technology acceptance and usage behavior (e.g., Theory of Planned Behavior; Ajzen, 1991) suggests that user perceptions fully mediate the effects of "external variables," which might include individual differences or training-based manipulations (i.e., "user acceptance enablers" in the context of this study) related to the system or its implementation (Davis et al., 1989; Venkatesh \& Davis, 1996). Therefore, we expect:

H4: Behavioral intention to use a new technology will be determined by intrinsic motivation, perceived usefulness, and perceived ease of use.

\section{Short-term and Continued Technology Usage}

Prior research in psychology and information systems (e.g., Ajzen, 1991; Ajzen \& Madden, 1986; Davis et al., 1989; Venkatesh \& Davis, 2000; Morris \& Venkatesh, 2000) has demonstrated that the relationship between user perceptions/motivations and actual short-term usage behavior is typically fully mediated by behavioral intention. Thus:

H5: An individual's actual technology usage behavior will be determined by behavioral intention to use the technology.

Prior longitudinal studies have demonstrated that the primary predictor of future behavior is past behavior (Bagozzi \& Kimmel, 1995; Conner \& Armitage, 1998; Norman \& Smith, 1995). In addition, a variety of studies have demonstrated that prior behavior has direct effects on future behavior that are not fully mediated 
by intentions (e.g., Ajzen \& Madden, 1986; Bagozzi, 1981; Bentler \& Speckart, 1979). The idea that direct experience with the behavior plays a very critical role in shaping future behavior is also supported by research examining attitudes (e.g., Fazio \& Zanna, 1978) and technology (e.g., Szajna \& Scammel, 1993; Venkatesh, 2000) - where direct experience overrides the effects of subsequent perceptions (i.e., perceptions of usefulness and ease of use). Thus, based on the strong evidence that prior behavior predicts future behavior, we expect that user perceptions (i.e., perceived usefulness, ease of use, and intrinsic motivation) measured at a later time will add no additional explanatory power in continued usage behavior beyond prior usage of the technology.

H6: Continued usage of technology will be predicted by short-term usage behavior.

\section{User Acceptance Enablers: Pre-training and Training Environment Manipulations}

A core theme that underlies this research is that both pre-training interventions and training environment manipulations (labeled "user acceptance enablers") can positively influence user perceptions, leading to greater technology usage both immediately after training and continued use post-training. Specific to intrinsic motivation, research has shown that training interventions can create an enhanced state of playfulness among users (Starbuck \& Webster, 1991; Webster \& Martocchio, 1992), thus making a training program more intrinsically motivating while continuing to provide adequate information to facilitate knowledge acquisition. Furthermore, play-like activities that increase intrinsic motivation are more likely to create "deep learning” in participants (e.g., Piaget, 1951).

$\mathrm{H} 7 \mathrm{a}$ : User acceptance enablers (pre-training and training environment manipulations) will have a positive influence on intrinsic motivation.

Similarly, training interventions can exert a positive influence on ease of use. For example, training methods that provide an overall conceptualization of the technology environment while at the same time incorporate hands-on use and exploratory learning have been found to be effective (Compeau \& Higgins, 1995; Olfman \& Mandviwalla, 1994; Santhanam \& Sein, 1994). Training interventions that incorporate more of these principles lead to more positive perceptions of ease of use post-training (Venkatesh \& Davis, 1996). Thus:

H7b: User acceptance enablers (pre-training and training environment manipulations) will have a positive influence on perceived ease of use.

\section{Model Efficacy}

While the prior theoretical development is important, a key issue is whether the integrated model developed here better explains user technology acceptance and use perceptions than either the technology acceptance or motivational models that serve as the primary theoretical framing of this research stream. The goal of any research model is to explain the variation associated with perceptions and behaviors 
as fully as possible. This goal must be balanced against the parsimony of any model (e.g., measuring 10 variables that explain an additional $2 \%$ of variance over the existing model would explain greater variance, but would be less parsimonious). Given the expected strength of the three predictors (intrinsic motivation, perceived usefulness, and perceived ease of use) when examined independently in past research, we believe that the proposed, integrated model will better model technology acceptance and usage outcomes.

Hence:

H8a: The integrated model (excluding user acceptance enablers) will be a better fit than the corresponding technology acceptance model.

H8b: The integrated model (excluding user acceptance enablers) will be a better fit than the corresponding motivational model.

H8c: The integrated model (including user acceptance enablers) will be a better fit than the corresponding technology acceptance model.

H8d: The integrated model (including user acceptance enablers) will be a better fit than the corresponding motivational model.

\section{RESEARCH METHOD}

In order to test the proposed model within the context of the existing research, data from the Venkatesh (1999) and Venkatesh and Speier (1999) studies were analyzed separately. Further, Venkatesh (1999) reported only one wave of data collection; the current research extends that by examining longitudinal data from that research project. Thus, the current work integrates theory across the prior two studies and extends that work through a longitudinal analysis. Due to space constraints, the reader is referred to the original works for methodological details of the two studies; however, details that are unique only to this paper are noted in the section that follows.

\section{Data Collection}

The data from Venkatesh (1999) were based on only one post-training wave of data collection. The current work extends the cross-sectional analysis presented in the initial research by collecting field data for an additional six months. Specifically, in order to provide a longitudinal perspective, user reactions were measured after three months, and usage was measured for the six-month period after the first wave of data collection (post-training). In the Venkatesh and Speier (1999) study, user reactions were measured three months after implementation, and usage was monitored during the six-month period following implementation.

\section{Extending and Integrating Existing Studies}

The integrated model was first tested using the data collected from the individual studies described in this section. Given the similar pattern of findings across both studies, we then pooled the data across both studies to examine the proposed model 
across a broader context of systems and organizational environments. To assess the validity of pooling data, user acceptance enabling (UAE) manipulations were coded $(0=$ training environment manipulation and $1=$ pre-training manipulation) to assess whether or not the training intervention resulted in a moderating influence on user acceptance perceptions and motivation. A significant interaction term would indicate differences in the strength of the individual UAE manipulations, while a nonsignificant interaction term would suggest that effects were equivalent. We found that the interaction terms were nonsignificant, thus suggesting that the data could be pooled. In the new sample, training environment (game-based) and pre-training environment (mood) manipulations were combined into a single user acceptance enabler manipulation labeled "positive enablers" while a control group was included representing hands-on training with no additional positive interventions.

\section{Measures}

Previously developed and validated scales using a 7-point Likert scale were used to measure the different constructs. Three of the four measures: perceived usefulness (U), perceived ease of use (EOU), and behavioral intention (BI) were developed and tested in Davis et al. (1989) and validated in a wide range of studies (e.g., Davis et al., 1992; Mathieson, 1991; Segars \& Grover, 1993; Taylor \& Todd, 1995; Szajna, 1996; Venkatesh, 1999; Venkatesh \& Speier, 1999). The scale for intrinsic motivation (IM) was developed and tested in Davis et al. (1992) and has been recently validated (Venkatesh \& Speier, 1999). Usage was an objective assessment of a participant's usage of a given technology based on the amount of time logged into the system.

Data were also collected using validated scales for two control variables: computer self-efficacy (Compeau \& Higgins, 1995) and playfulness (Webster \& Martocchio, 1992) and to validate the experimental manipulations. The effectiveness of the pre- and during-training manipulations were measured and tested, and are reported in the original studies (see Venkatesh, 1999; Venkatesh \& Speier, 1999). Manipulation checks indicated that these manipulations had the desired effect on users of each system.

In both studies, participants completed an instrument measuring all perceived usefulness, perceived ease of use, intrinsic motivation, and intention to use variables immediately after training. Usage was then tracked for 12 weeks, creating the measure of short-term use. Perceptual, motivational, and intention measures were taken again at this time, and subsequent actual technology usage was tracked for an additional 12 weeks.

\section{RESULTS}

EQS, a structural equation modeling technique, was used to analyze the data (see Table 1). All constructs satisfied the criteria of reliability (Cronbach alpha greater than .90 ) and convergent and discriminant validity. This pattern of high reliability and validity was consistent with our expectations given that the scales for the constructs had been extensively tested and validated in prior research on technology acceptance (e.g., Davis et al., 1992). The intercorrelations among the various constructs are provided in Table 2 and are all within an acceptable range. 
Table 1: Measurement model estimation.

\begin{tabular}{lll}
\hline Intrinsic & Motivation & $\mathbf{9 1}$ \\
IM1 & I find the system to be enjoyable. & .88 \\
IM2 & The actual process of using the system is pleasant. & .94 \\
IM3 & I have fun using the system. & .91 \\
Perceived & Ease of Use & $\mathbf{9 4}$ \\
EOU1 $\quad$ My interaction with the system is clear and understandable. & .90 \\
EOU2 & Interacting with the system does not require a lot of my mental effort. & .93 \\
EOU3 & I find the system to be easy to use. & .94 \\
EOU4 & I find it easy to get the system to do what I want it to do. & .95 \\
Perceived Usefulness & .91 \\
U1 & Using the system improves my performance in my job. \\
U2 & Using the system in my job increases my productivity. & .90 \\
U3 & Using the system enhances my effectiveness on the job. & .91 \\
U4 & I find the system to be useful in my job. & .89 \\
Behavioral Intention & .92 \\
BI1 & Assuming I had access to the system, I intend to use it. & \\
BI2 & Given that I had access to the system, I predict that I would use it. & .90 \\
\hline
\end{tabular}

In order to test the model, a dummy variable UAE was introduced, with 0 representing a UAE environment (game-based training or mood) and 1 representing a control group involving a traditional hands-on training environment. Thus, for the purpose of the structural model estimation, the data were pooled across pretraining and "within" training interventions. This was deemed to be acceptable given the non-significant mean differences and comparable path coefficient between the two interventions. Figure 4 provides the results of the path model estimation for the integrated model.

The presented integrated theory suggested that IM would influence EOU and $U$; EOU would influence $U$; and IM, EOU, and $U$ would all have significant positive effects on BI. Structural equation modeling results support the influence of IM on EOU $(.45, p<.001)$, supporting H1, and IM on $\mathrm{U}(.27, p<.001)$, supporting H2. Similarly, EOU influences U significantly $(.27, p<.001)$, supporting H3. There was partial support for $\mathrm{H} 4$ : $\operatorname{EOU}(.23, p<.001)$ and $\mathrm{U}(.44, p<.001)$ had a significant effect on BI. Contrary to expectations, IM had no direct influence on $\mathrm{BI}(.07, p>.05)$, and instead operated indirectly through both $\mathrm{U}$ and EOU.

As expected, BI was the only significant determinant of immediate usage behavior (USE12) $(.59, p<.001)$, fully mediating the influence of IM, EOU, and $\mathrm{U}$, thus supporting H5. Finally, immediate use (USE12) was the sole significant predictor of continued usage (USE23) $(.59, p<.001)$-all other variables measured at $\mathrm{t} 1$ and $\mathrm{t} 2$ were non-significant predictors of USE23 (i.e., they did not account for any additional variance in continued use beyond what was explained by USE12), thus supporting H6. 


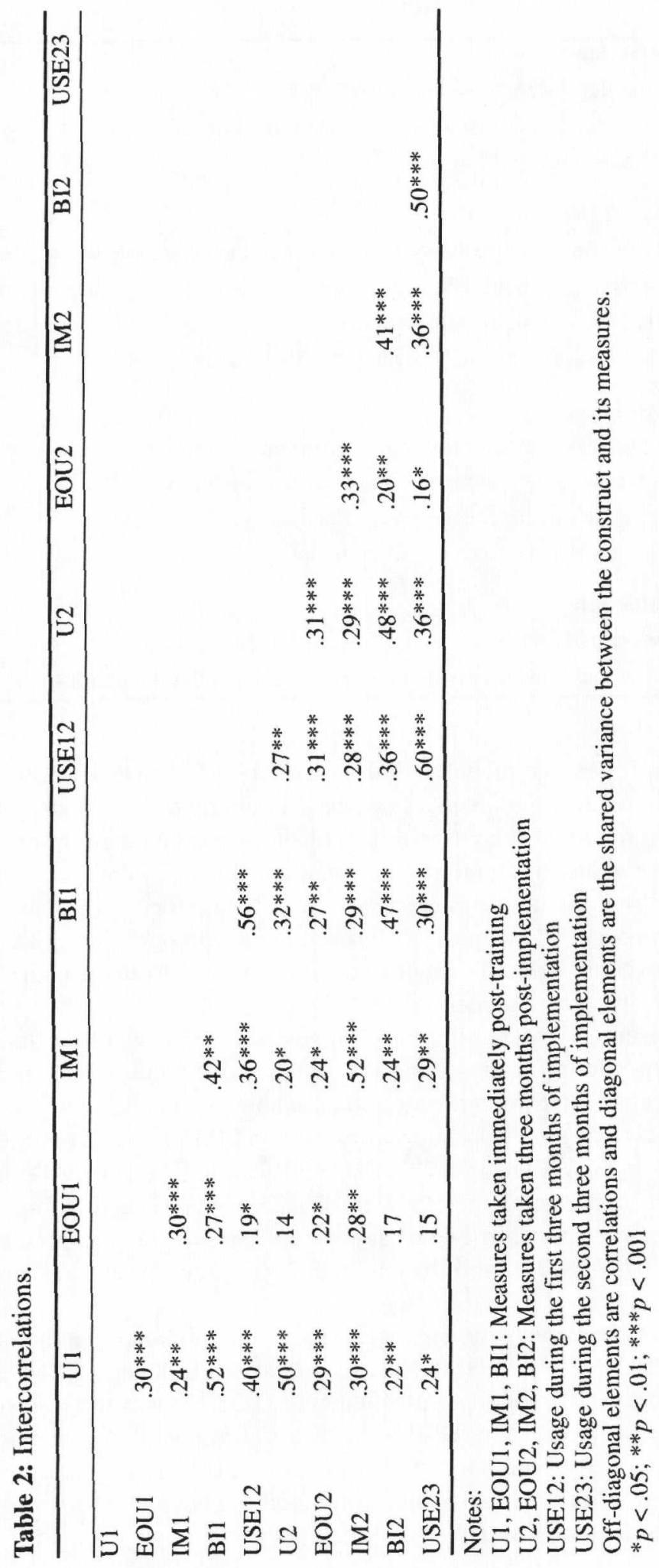




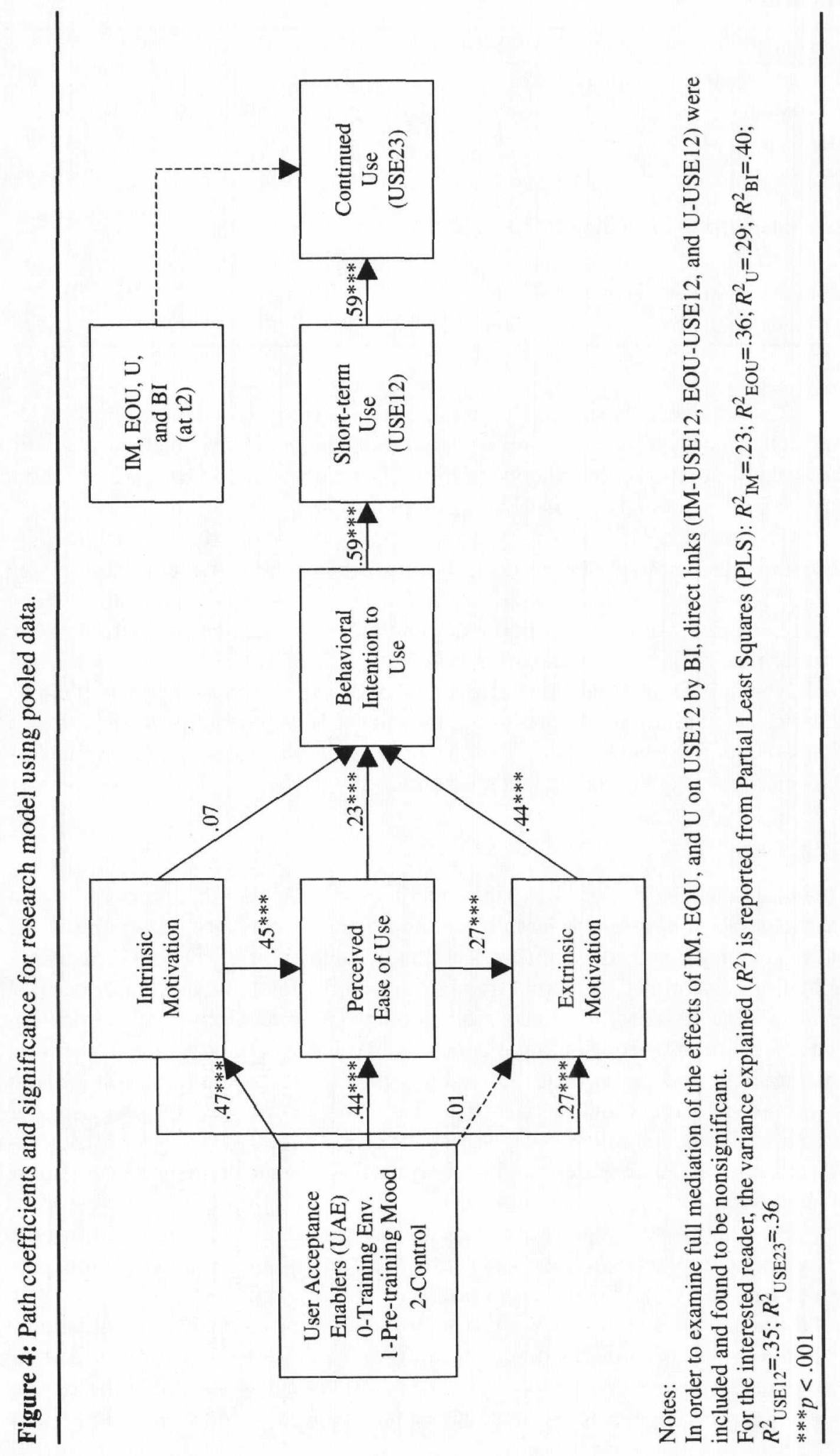


Table 3: Fit statistics.

\begin{tabular}{lccccccc}
\hline Model & CFI & RMSEA & GFI & AGFI & AIC & CAIC & $\chi^{2}$ \\
\hline Baseline Model (excluding UAE) & & & & & & \\
TAM Model & .88 & .10 & .88 & .87 & 128.72 & -324.12 & 338.23 \\
Motivational Model & .86 & .09 & .84 & .86 & 124.88 & -323.88 & 340.24 \\
Integrated Model & .90 & .08 & .91 & .90 & 88.85 & -341.25 & 297.52 \\
& & & & & & & \\
Expanded Model (including UAE) & & & & & \\
TAM Model & .90 & .08 & .90 & .90 & 111.71 & -360.41 & 301.25 \\
Motivational Model & .89 & .08 & .88 & .89 & 106.40 & -351.28 & 308.15 \\
Integrated Model & .92 & .06 & .93 & .93 & 70.22 & -388.91 & 271.71 \\
\hline
\end{tabular}

The user acceptance enabler manipulations were expected to influence IM and EOU significantly. Structural equation modeling results were consistent with these expectations: UAEs influenced IM $(.47, p<.001)$ and EOU $(.44, p<.001)$, but not $\mathrm{U}(.01, p>.05)$. Thus, $\mathrm{H} 7$ was supported.

The integrated model was expected to be a better fit than both the technology acceptance and motivational models, and structural equation modeling results (see Table 3 ) confirmed these expectations. While the $\chi^{2}$ was significant in all cases, in larger samples, a significant finding does not provide meaningful discrimination. Furthermore, all other fit statistics (e.g., CFI, RMSEA, GFI, AGFI, AIC, and CAIC) work in favor of the integrated model; thus, H8a-d were supported. It is also noteworthy that any model including user acceptance enablers was a better fit compared to its baseline model. This is to be expected as user acceptance enablers showed strong, significant path coefficients.

\section{DISCUSSION}

This research has developed and tested an integrated model that helps unify two parallel streams of research on information systems acceptance. In doing so, this integrated model provides a much richer understanding of the factors influencing technology use immediately after training, and more importantly, over an extended period of time. Although intrinsic motivation had no direct influence on intention to use technology, one should not conclude that intrinsic motivation is therefore not important. Rather, intrinsic motivation served as an important catalyst for both perceived usefulness and perceived ease of use--both important predictors of intentions to use technology-suggesting that the indirect role of intrinsic motivation is a critical one in understanding short-term acceptance or rejection decisions of new users.

From a theoretical perspective, as a predictor of intention, the effects of the tested user acceptance enablers were fully mediated by intrinsic motivation, perceived ease of use, and perceived usefulness. This suggests that both pre-training and training environment interventions play a pivotal role in shaping initial user motivations and perceptions that, in turn, form the bases for intentions and technology use over time. While the design of this study necessitated that these were looked at independently, the results suggest that managerial interventions aimed at 
both types of UAEs might be a powerful strategy for inducing widespread adoption and use of new technology.

Within our baseline integrated model of technology acceptance, it is interesting to note that perceived usefulness had a very strong positive effect on intention to use information technology, yet training interventions did not influence perceived usefulness. In addition, perceived ease of use had a strong influence on intention over and above that of perceived usefulness while intrinsic motivation exerted a significant indirect influence on intention. Given the strong direct and indirect influences of ease of use and intrinsic motivation, technology acceptance initiatives should focus on interventions designed to increase perceptions that the technology is easy and enjoyable to use. The implications for addressing perceived usefulness through UAEs is less clear. Strictly looking at the results, one could conclude that there is no value gained by developing UAEs designed to increase usefulness perceptions about a technology. However, there is research demonstrating that other potential UAEs (e.g., subjective norm) can influence usefulness perceptions (Venkatesh \& Davis, 2000; Galletta, Ahuja, Hartman, Teo, \& Peace, 1995). Additional research is needed to better understand the contingencies associated with different user, technology, and organizational environments that can directly affect perceived usefulness-particularly when one considers the critical role that perceived usefulness plays in influencing intention to use a technology.

One implication of the results of this study is that those responsible for technology implementation should beta test new technologies (built or bought) with small groups of diverse users to better understand perceptual and motivational reactions. Attending to user concerns in the analysis and design phases of a technology decision can have important payoffs for managers attempting to implement new technologies. These findings suggest that it is important to get user "buy-in" during technology design and/or selection to help eliminate usability problems early in the design process. Waiting until a system is deployed and then collecting feedback from users to assist with bug fixes or revisions is probably dangerous at best. Once the system is fielded, it is often too late to have any real impact on system design (Landauer, 1995) and, per the findings of this research, managers struggling to implement the system may have already seriously damaged chances for system acceptance and success.

Given the demonstrated critical role for user acceptance enablers, organizations who desire to outsource their training function may consider contracting mechanisms that reward innovative training techniques or require user validation of training quality versus more traditional fixed price contracts. Regardless of whether training is outsourced or kept as an in-house function, the current research suggests that training should not be considered ancillary-rather, it is an essential component in the technology acceptance equation. Again, regardless of the mechanism chosen for delivering that training, organizations will likely have different orientations and capabilities associated with technology training and, therefore, assessing the perceptions and motivations of beta users to different training sessions would provide insights into those training organizations that can maximize technology acceptance within a firm.

Finally, this research further emphasizes the importance of early (i.e., shortterm) perceptions and acceptance decisions by users. From a longitudinal perspec- 
tive, the perceptions formed immediately following training are critical-not only to early acceptance decisions, but to continued usage as well. Subsequent user perceptions and motivation had no significant effect on short-term use--suggesting that once users are "turned off" to a system, fixes to that system, redesign, or encouragement from others are not likely to play a major role in getting users to adopt the system over time. Systems that are introduced and used immediately, but ultimately rejected over time by users are likely to result in significant expenditures of organizational resources (money, time, personnel) in attempting to discover why the system fell into disuse and in correcting flaws in the system. The current research indicates that, in trying to gain acceptance for continued and extended technology use, such fixes are likely to be an uphill battle. Thus, this research suggests that positive pre-training and training environment interventions can be used as a catalyst for increasing intrinsic motivation and perceived ease of use-important success factors in both initial and enduring acceptance of new technology by end users within the organization.

\section{Limitations and Suggestions for Future Research}

While a strength of this study involved the use of two samples and technologies to both integrate and extend existing theory, future research should nonetheless test this integrated theory across a broader set of technologies and user populations to determine its predictive robustness. For example, participants within their firms used the technologies investigated here voluntarily; however, future research might investigate the merits of the integrated theory when looking at mandatory use of technology.

Furthermore, this research has highlighted the importance of both the pretraining and training environment in understanding acceptance of technology over time. This research focused on those two specific user acceptance enhancers due to their strong theoretical linkage to the psychological models of human behavior that framed the current study. However, future research may usefully examine other potential user acceptance enhancers as a means for extending the nomological network within the domain.

\section{CONCLUSION}

The importance of understanding and influencing information technology acceptance within organizations is critical given the annual investment into technology and technology training. Results from this research better identify the determinants of technology usage by extending and integrating two important theories (TAM and the motivational model) that have guided much of the past research on technology acceptance. The integrated model presented here allows researchers to focus on key antecedents to intention and usage behavior and understand how each of these antecedents explain variance across samples and technologies. Furthermore, by including multiple types of user acceptance enablers, one is able to assess the degree to which each of the acceptance antecedents are affected. Finally, by testing the model longitudinally, the present research presents a dynamic model demonstrating the salience of the user acceptance enablers and the antecedents to 
intentions and usage over time. We are unaware of any research that incorporates all of these facets simultaneously to create a robust understanding of individual adoption and use of technology. As a result, we believe that the integrated theory developed here provides researchers and practitioners with a much richer tool to proactively assess technology acceptance in organizational settings. [Received: January 22, 2001. Accepted: February 7, 2002.]

\section{REFERENCES}

Adams, D., Nelson, R. R., \& Todd, P. (1992). Perceived usefulness, ease of use and usage of information technology: A replication. MIS Quarterly, 16, 227-248.

Ajzen, I. (1991). The theory of planned behavior. Organizational Behavior and Human Decision Processes, 50, 179-211.

Ajzen, I., \& Madden, T. J. (1986). Prediction of goal-directed behavior: Attitudes, intentions, and perceived behavioral control. Journal of Experimental Social Psychology, 22, 453-474.

Bagozzi, R. P. (1981). Attitudes, intentions, and behavior: A test of some key hypotheses. Journal of Personality and Social Psychology, 41, 607-627.

Bagozzi, R. P., Gopinath, M., \& Nyer, P. U. (1999). The role of emotions in marketing. Journal of the Academy of Marketing Science, 27, 184-206.

Bagozzi, R. P., \& Kimmel, S. K. (1995). A comparison of leading theories for the prediction of goal-directed behaviors. British Journal of Social Psychology, $34,437-461$.

Batra, R., \& Ray, M. L. (1986). Affective responses mediating acceptance of advertising. Journal of Consumer Research, 13, 234-249.

Bentler, P. M., \& Speckart, G. (1979). Attitudes cause behaviors: A structured equation analysis. Journal of Personality and Social Psychology, 40, 226238.

Calder, B. J., \& Staw, B. M. (1975). Self perception of intrinsic and extrinsic motivation. Journal of Personality and Social Psychology, 31, 599-603.

Compeau, D. R., \& Higgins, C. A. (1995). Application of social cognitive theory to training for computer skills. Information Systems Research, 6, 118-143.

Conner, M., \& Armitage, C. J. (1998). Extending the theory of planned behavior: A review and avenues for further research. Journal of Applied Social Psychology, 28, 1429-1464.

Davis, F. D. (1989). Perceived usefulness, perceived ease of use, and user acceptance of information technology. MIS Quarterly, 13, 319-339.

Davis, F. D., Bagozzi, R. P., \& Warshaw, P. R. (1989). User acceptance of computer technology: A comparison of two theoretical models. Management Science, 35, 982-1002.

Davis, F. D., Bagozzi, R. P., \& Warshaw, P. R. (1992). Extrinsic and intrinsic motivation to use computers in the workplace. Journal of Applied Social Psychology, 22, 1111-1132. 
Deci, E. L. (1975). Intrinsic motivation. New York: Plenum Press.

Fazio, R. H., \& Zanna, M. (1978). Attitudinal qualities relating to the strength of the attitude-perception and attitude-behavior relationship. Journal of Experimental Social Psychology, 14, 398-408.

Galletta, D. F., Ahuja, M. K., Hartman, A., Teo, T., \& Peace, A. G. (1995). Social influence and end user computing. Communications of the ACM, 37(7), 7079.

IDC. (2001). Slowing economy spurs IT education and training spending. Recovered from the World Wide Web, June 4, 2001: http://www.idc.com/getdoc.jhtml?containerId=pr2001_09_02_142818.

Landauer, T. K. (1995). The trouble with computers: Usefulness, usability, and productivity. Cambridge, MA: MIT Press.

Mano, H. (1992). Judgments under distress: Assessing the role of unpleasantness and arousal in judgment formation. Organizational Behavior and Human Decision Processes, 52, 389-411.

Mathieson, K. (1991). Predicting user intentions: Comparing the technology acceptance model with the theory of planned behavior. Information Systems Research, 2, 173-191.

Morris, M., \& Dillon, A. (1997). How user perceptions influence software use. IEEE Software, 14, 58-65.

Morris, M. G., \& Venkatesh, V. (2000). Age differences in technology adoption decisions: Implications for a changing workforce. Personnel Psychology, 53, 375-403.

Norman, P., \& Smith, L. (1995). The theory of planned behaviour and exercise: An investigation into the role of prior behaviour, behavioural intentions and attitude variability. European Journal of Social Psychology, 25, 403-415.

Olfman, L., \& Mandviwalla, M. (1994). Conceptual versus procedural software training for graphical user interfaces: A longitudinal field experiment. MIS Quarterly, 18, 405-426.

Piaget, J. (1951). Play, dreams and imitation in childhood. New York: Norton.

Santhanam, R., \& Sein, M. K. (1994). Improving end-user efficiency: Effects of conceptual training and nature of interaction. Information Systems Research, $5,378-399$.

Segars, A. H., \& Grover, V. (1993). Re-examining perceived ease of use and usefulness: A confirmatory factor analysis. MIS Quarterly, 17, 517-525.

Starbuck, W., \& Webster, J. (1991). When is play productive? Accounting, Management and Information Technology, 1, 71-90.

Szajna, B. (1996). Empirical evaluation of the revised technology acceptance model. Management Science, 42, 85-92.

Szajna, B., \& Scamell, R. W. (1993). The effects of information system user expectations on their performance and perceptions. MIS Quarterly, 18, 493-516.

Tannenbaum, S. I. (1990). Human resource information systems: User group implications. Journal of Systems Management, 41, 27-32. 
Taylor, S., \& Todd, P. (1995). Understanding information technology usage: A test of competing models. Information Systems Research, 6, 144-176.

Vallerand, R. J., Fortier, M., \& Guay, F. (1997). Self-determination and persistence in a real-life setting: Toward a motivational model of high school dropout. Journal of Personality and Social Psychology, 72, 1161-1177.

Venkatesh, V. (1999). Creation of favorable user perceptions: Exploring the role of intrinsic motivation. MIS Quarterly, 23, 239-260.

Venkatesh, V. (2000). Determinants of perceived ease of use: Integrating control, intrinsic motivation, and emotion into the technology acceptance model. Information Systems Research, 11(4), 342-365.

Venkatesh, V., \& Davis, F. D. (1996). A model of the antecedents of perceived ease of use: Development and test. Decision Sciences, 27, 451-481.

Venkatesh, V., \& Davis, F. D. (2000). A theoretical extension of the technology acceptance model: Four longitudinal field studies. Management Science, 46, 186-204.

Venkatesh, V., \& Morris, M. G. (2000). Why don't men ever stop to ask for directions? Gender, social influence, and their role in technology acceptance and usage behaviour. MIS Quarterly, 24(1), 115-138.

Venkatesh, V., \& Speier, C. (1999). Computer technology training in the workplace: A longitudinal investigation of the effect of mood. Organizational Behavior and Human Decision Processes, 79, 1-28.

Webster, J., \& Martocchio, J. J. (1992). Microcomputer playfulness: Development of a measure with workplace implication. MIS Quarterly, 16, 201-226.

Viswanath Venkatesh is a Tyser Fellow and assistant professor in decision and information technologies. He completed his $\mathrm{PhD}$ in information and decision sciences from the University of Minnesota in 1997. His research has been published in leading information systems, organizational behavior, and psychology journals such as Management Science, MIS Quarterly, Information Systems Research, Organizational Behavior and Human Decision Processes, Decision Sciences, and Personnel Psychology. He was a recipient of the Robert H. Smith School's highest teaching award, "Krowe Award for General Excellence," in 2000. He was also a recipient of the Smith School's "Teaching Innovation Award" in 1998 and 2001. He has been an adhoc reviewer for many journals; MIS Quarterly named him "Reviewer of the Year" in 1999. Beginning in 2000, he is also serving on MIS Quarterly's editorial board as an associate editor.

Cheri Speier is an associate professor of information systems at Michigan State University. Her research interests include the influence of work environments on decision making, individual acceptance and use of technology, effective user training environments, and the effective use of information technology to support supply chain relationships. Her work has appeared in journals such as Decision Sciences, Organizational Behavior and Human Decision Processes, Journal of Marketing, Information \& Management, and International Journal of Human Computer Interaction, among others. Dr. Speier was awarded the MSU University- 
wide Teacher Scholar award in 2001, recognizing her excellence in teaching and research. She earned a $\mathrm{PhD}$ in management information systems at Indiana University.

Michael G. Morris is an assistant professor of commerce within the Information Technology (IT) area at the McIntire School of Commerce, University of Virginia. Prior to joining McIntire in 2001, he served 15 years as an officer in the United States Air Force and was on the faculty of the Air Force Institute of Technology. He received his $\mathrm{PhD}$ in management information systems from Indiana University in 1996. His research interests can be classified broadly as socio-cognitive aspects of human response to information technology, including user acceptance of information technology, usability engineering, and decision making. His research has been published in MIS Quarterly, Organizational Behavior and Human Decision Processes, Decision Sciences, and Personnel Psychology, among others. 